\title{
Comparison of respiratory mechanics between sevoflurane and propofol-remifentanil anesthesia for laparoscopic colectomy
}

\author{
Si Ra Bang ${ }^{1}$, Sang Eun Lee ${ }^{1}$, Hyun Joo $\mathrm{Ahn}^{2}$, Jie Ae Kim², Byung Seop Shin ${ }^{2}$, Hee Jin Roe ${ }^{2}$, and \\ Woo Seog Sim $^{2}$ \\ Department of Anesthesiology and Pain Medicine, ${ }^{1}$ Haeundae Paik Hospital, Inje University School of Medicine, Busan, \\ ${ }^{2}$ Samsung Medical Center, Sungkyunkwan University School of Medicine, Seoul, Korea
}

Background: The creation of pneumoperitoneum and Trendelenburg positioning during laparoscopic surgery are associated with respiratory changes. We aimed to compare respiratory mechanics while using intravenous propofol and remifentanil vs. sevoflurane during laparoscopic colectomy.

Methods: Sixty patients undergoing laparoscopic colectomy were randomly allocated to one of the two groups: group PR (propofol-remifentanil group; $\mathrm{n}=30$ ), and group $\mathrm{S}$ (sevoflurane group; $\mathrm{n}=30$ ). Peak inspiratory pressure (PIP), dynamic lung compliance (Cdyn), and respiratory resistance (Rrs) values at five different time points: 5 minutes after induction of anesthesia (supine position, T1), 3 minutes after pneumoperitoneum (lithotomy position, T2), 3 minutes after pneumoperitoneum while in the lithotomy-Trendelenburg position (T3), 30 minutes after pneumoperitoneum (T4), and 3 minutes after deflation of pneumoperitoneum (T5).

Results: In both groups, there were significant increases in PIP and Rrs while Cdyn decreased at times T2, T3, and T4 compared to T1 $(\mathrm{P}<0.001)$. The Rrs of group PR for T2, T3, and T4 were significantly higher than those measured in group $\mathrm{S}$ for the corresponding time points $(\mathrm{P}<0.05)$.

Conclusions: Respiratory mechanics can be adversely affected during laparoscopic colectomy. Respiratory resistance was significantly higher during propofol-remifentanil anesthesia than sevoflurane anesthesia. (Korean J Anesthesiol 2014; 66: 131-135)

Key Words: Laparoscopy, Propofol, Remifentanil, Respiratory mechanics, Sevoflurane.

Received: November 15, 2012. Revised: 1st, March 8, 2013; 2nd, June 12, 2013; 3rd, July 26, 2013. Accepted: August 14, 2013.

Corresponding author: Woo Seog Sim, M.D., Ph.D., Department of Anesthesiology and Pain Medicine, Samsung Medical Center, Sungkyunkwan University School of Medicine, 50, Ilwon-dong, Gangnam-gu, Seoul 135-710, Korea. Tel: 82-2-3410-0356, Fax: 82-2-3410-0361, E-mail: anesthe@ skku.edu

(c) This is an open-access article distributed under the terms of the Creative Commons Attribution Non-Commercial License (http:// creativecommons.org/licenses/by-nc/3.0/), which permits unrestricted non-commercial use, distribution, and reproduction in any medium, provided the original work is properly cited. 


\section{Introduction}

Laparoscopic colectomy is increasingly being performed because it is minimally invasive technique and therefore associated with decreased blood loss, a shorter hospital stay and fewer wound problems than open colectomy [1,2]. However, the creation of pneumoperitoneum and Trendelenburg positioning for this procedure are associated with an increase in airway pressure and a decrease in lung compliance, as well as barotrauma [3]. These alterations in respiratory mechanics could adversely affect patient outcomes.

Both total intravenous anesthesia with propofol-remifentanil and inhalation anesthesia with sevoflurane are widely used. Generally, both sevoflurane and propofol can decrease respiratory resistance (Rrs) or peak inspiratory pressure (PIP), and/ or increase dynamic compliance (Cdyn) [4-13]. In contrast, opioids can induce chest wall rigidity but effectively be reversed by neuromuscular blocking agents $[14,15]$. A previous experimental study concluded that propofol assured better respiratory conditions than sevoflurane during laparoscopic surgery [4]. However, that study was conducted using a porcine model.

Our purpose in this study was to compare the respiratory mechanics of patients anesthetized by intravenous propofolremifentanil vs. inhalant sevoflurane during laparoscopic colectomy.

\section{Materials and Methods}

This study was performed after approval from the local institutional review board. Written informed consent was obtained from all patients. Sixty patients, aged between 40 and 75 years old, with American Society of Anesthesiologists physical status I and II who were scheduled to undergo laparoscopic colectomy were enrolled from August 2009 to December 2009. Patients with cardiovascular disease, pulmonary disease, morbid obesity ( $>20 \%$ heavier than ideal body weight), or who were current smokers were excluded from the study.

Patients were allocated randomly to one of two groups: group PR (propofol-remifentanil group; $\mathrm{n}=30$ ), or group S (Sevoflurane group; $\mathrm{n}=30$ ) using a computer-generated table of random numbers. Patients were not premedicated. Hemodynamics were monitored standardly with non-invasive blood pressure, oxygen saturation and electrocardiography.

To induce anesthesia, all patients were ventilated with $100 \%$ $\mathrm{O}_{2}$ in a mask. In group PR, after intravenous injection of 20 mg lidocaine, propofol (Fresofol MCT 2\% Inj., Fresenius Kabi, Graz, Austria) and remifentanil hydrochloride (Ultiva ${ }^{\circledR}$, GlaxoSmithKline, Parma, Italy) were administered at $5 \mu \mathrm{g} / \mathrm{ml}$ and 3 $\mathrm{ng} / \mathrm{ml}$, respectively, using an effect-site concentration targetcontrolled infusion pump (Orchestra ${ }^{\circledR}$, Fresenius Vial, Brezins,
France). In group $S$, anesthesia was induced with propofol (Pofol inj., Jeil Pharm CO., Seoul, Korea) $2 \mathrm{mg} / \mathrm{kg}$, fentanyl $1 \mu \mathrm{g} / \mathrm{kg}$ and sevoflurane. All patients were intubated with a $7.5 \mathrm{~mm}$ internal diameter endotracheal tube at about $3 \mathrm{~min}$ after injection of 0.8 $\mathrm{mg} / \mathrm{kg}$ rocuronium.

During maintenance of anesthesia, propofol and remifentanil infusions or sevoflurane were titrated to maintain a mean blood pressure within $20 \%$ of baseline. All patients were ventilated with a fixed protocol: a tidal volume of about $8 \mathrm{ml} / \mathrm{kg}$, 12 breaths/minute, and an inspiratory-to-expiratory ratio of 1 : 2 in $1.5 \mathrm{~L} / \mathrm{min}$ of $\mathrm{O}_{2}$-air mixture at $\mathrm{FiO}_{2} 0.5$ using a ventilator (Aestiva/5, Datex Ohmeda, Helsinki, Finland). Muscle relaxation was maintained between $90-95 \%$ in response to a train of four stimulations with continuous infusion of $0.05 \mathrm{mg} / \mathrm{kg} / \mathrm{hr}$ vecuronium. Patients who were injected with any other drugs for hemodynamic control or anesthesia, or whose position changed for any reason before data were collected, were excluded from this study.

A disposable spirometry tube was connected to the proximal end of the tracheal tube. Respiratory mechanics were displayed and measured using an anesthesia monitor (Datex Ohmeda $\mathrm{S} / 5^{\mathrm{TM}}$ compact anesthesia monitor, General electric, Helsinki, Finland).

Intraabdominal $\mathrm{CO}_{2}$ pressure was maintained at around 12 $\mathrm{mmHg}$ during pneumoperitoneum in a lithotomy position. The operative table had a head-down tilt of 20 degrees to place the patient in the Trendelenburg position. Respiratory mechanical parameters (PIP, Cdyn and Rrs) were recorded at five different time points: 5 minutes after induction of anesthesia (supine position, T1), 3 minutes after pneumoperitoneum (lithotomy position, T2), 3 minutes after pneumoperitoneum while in the lithotomy-Trendelenburg position (T3), 30 minutes after pneumoperitoneum (T4), and 3 minutes after deflation of pneumoperitoneum (T5). We calculated the mean value of data measured three times during three consecutive ventilations during periods when the compliance loops were not distorted by any interference, such as instrument changes.

Statistical analysis was performed with the software program SAS 9.1.3 (SAS Institute, Inc., Cary, NC, USA). Sample size was determined based on a preliminary study. To be able to measure a 15\% difference in PIP between two groups with a power of $80 \%$ and an alpha error of 0.05 , we calculated that the minimum sample size required was 28 patients per group. We therefore included 30 patients in each group to account for dropout.

Demographic data were compared using a two-sample t-test or chi-square test. Changes in respiratory mechanic parameter values with time were analyzed by repeated measures analysis of variance (ANOVA) with Bonferroni correction for post hoc comparisons. Data are reported as mean \pm SD. A P value $<0.05$ was considered statistically significant. 


\section{Results}

Patient characteristics were not different between the two groups (Table 1). All patients were hemodynamically stable. No episodes of desaturation occured.

In all groups, there was a significant increase in PIP and Rrs, and a decrease in Cdyn at T2, T3, and T4 compared to T1 (P < 0.001 ) (Table 2). Respiratory mechanic parameters were not significantly different at T3 and T4 compared to T2, while those at T5 were restored to values similar to those measured at T1 (Table 2).

PIP and Cdyn were not significantly different between the two groups at any time point (Table 2). Only Rrs was significantly higher during propofol-remifentanil anesthesia than during sevoflurane anesthesia at T2, T3, and T4 $(\mathrm{P}<0.05)$ (Table 2).

Table 1. Patient Characteristics, Duration of Anesthesia and Surgery

\begin{tabular}{lcc}
\hline & Group PR $(\mathrm{n}=30)$ & Group S $(\mathrm{n}=30)$ \\
\hline Sex $(\mathrm{M} / \mathrm{F})$ & $16 / 14$ & $18 / 12$ \\
Age $(\mathrm{yr})$ & $59.4 \pm 10.9$ & $54.3 \pm 10.6$ \\
Height $(\mathrm{cm})$ & $160.8 \pm 10.3$ & $160.2 \pm 7.8$ \\
Weight $(\mathrm{kg})$ & $63.5 \pm 9.8$ & $61.5 \pm 8.6$ \\
Body mass index $\left(\mathrm{kg} / \mathrm{m}^{2}\right)$ & $24.5 \pm 2.4$ & $23.9 \pm 2.5$ \\
ASA I/II $(\mathrm{n})$ & $13 / 17$ & $16 / 14$ \\
Anesthetic time $(\mathrm{min})$ & $189.7 \pm 53.3$ & $204.0 \pm 58.5$ \\
Operation time $(\mathrm{min})$ & $152.1 \pm 53.3$ & $165.5 \pm 59.2$ \\
\hline
\end{tabular}

Data are expressed as number or mean \pm standard deviation. Group PR: propofol-remifentanil group, Group S: sevoflurane group.

Table 2. Changes in Respiratory Mechanic Parameters at Different Times

\begin{tabular}{|c|c|c|c|}
\hline Variable & Situation & Group PR & Group S \\
\hline \multirow{5}{*}{$\begin{array}{l}\text { Peak inspiratory pressure } \\
\left(\mathrm{cmH}_{2} \mathrm{O}\right)\end{array}$} & $\mathrm{T} 1$ & $15.5 \pm 3.0$ & $14.6 \pm 2.8$ \\
\hline & $\mathrm{T} 2$ & $24.4 \pm 5.1^{*}$ & $23.2 \pm 5.0^{*}$ \\
\hline & $\mathrm{T} 3$ & $25.5 \pm 4.8^{*}$ & $23.8 \pm 5.2^{*}$ \\
\hline & $\mathrm{T} 4$ & $27.1 \pm 5.1^{*}$ & $25.4 \pm 4.6^{*}$ \\
\hline & T5 & $17.8 \pm 3.4$ & $17.8 \pm 3.3$ \\
\hline \multirow{5}{*}{$\begin{array}{l}\text { Dynamic compliance } \\
\left(\mathrm{ml} / \mathrm{cmH}_{2} \mathrm{O}\right)\end{array}$} & $\mathrm{T} 1$ & $63.3 \pm 15.6$ & $63.2 \pm 14.5$ \\
\hline & $\mathrm{T} 2$ & $33.6 \pm 10.1^{*}$ & $35.5 \pm 12.7^{*}$ \\
\hline & T3 & $31.3 \pm 9.3^{*}$ & $33.4 \pm 11.4^{*}$ \\
\hline & $\mathrm{T} 4$ & $30.2 \pm 10.3^{*}$ & $30.4 \pm 7.2^{*}$ \\
\hline & T5 & $51.4 \pm 12.1$ & $51.0 \pm 13.4$ \\
\hline \multirow{5}{*}{$\begin{array}{l}\text { Respiratory resistance } \\
\left(\mathrm{ml} / \mathrm{cmH}_{2} \mathrm{O} / \mathrm{s}\right)\end{array}$} & $\mathrm{T} 1$ & $9.8 \pm 2.9$ & $8.4 \pm 2.9$ \\
\hline & $\mathrm{T} 2$ & $12.7 \pm 5.6^{*,+}$ & $10.6 \pm 4.0^{*,+}$ \\
\hline & T3 & $12.9 \pm 5.3^{*, \dagger}$ & $10.5 \pm 3.2^{*,+}$ \\
\hline & $\mathrm{T} 4$ & $12.0 \pm 4.5^{*, \dagger}$ & $10.3 \pm 3.4^{*,+}$ \\
\hline & T5 & $8.5 \pm 2.4$ & $7.5 \pm 1.7$ \\
\hline
\end{tabular}

All values are expressed as mean \pm standard deviation. Group PR: propofol-remifentanil group, Group S: sevoflurane group. T1: 5 minutes after induction of anesthesia (supine position), T2: 3 minutes after pneumoperitoneum (lithotomy position), T3: 3 minutes after pneumoperitoneum while in the lithotomy-Trendelenburg position, T4: 30 minutes after pneumoperitoneum, T5: 3 minutes after deflation of pneumoperitoneum. $* \mathrm{P}<0.001$ compared to $\mathrm{T} 1$ value in each group. ${ }^{\dagger} \mathrm{P}<0.05$ compared between groups.

\section{Discussion}

The use of intravenous propofol-remifentanil or inhalant sevoflurane during laparoscopic colectomy was associated with an increase in PIP and Rrs a decrease in Cdyn values during the creation of pneumoperitoneum and when patients were in the Trendelenburg position. Patients in group PR had significantly higher respiratory resistance values than those in group $\mathrm{S}$ during the creation of pneumoperitoneum and placement in the Trendelenburg position.

We measured respiratory mechanic parameters using a computed side stream monitor. Lung compliance (C) and airway resistance (Raw) were calculated for each breath from the following equation: $\mathrm{C}=\mathrm{TV} \exp /($ Pplat-PEEP) and $\mathrm{P}(\mathrm{t})=\mathrm{Raw} \mathrm{dV} / \mathrm{dt}+$ $\mathrm{V}(\mathrm{t}) / \mathrm{C}+\mathrm{PEEP}$, where TVexp $=$ expiratory tidal volume, Pplat $=$ end-inspiratory lung pressure, PEEP = positive end-expiratory lung pressure, and $\mathrm{P}(\mathrm{t})$ and $\mathrm{V}(\mathrm{t})=$ pressure and volume at a certain time ( $\mathrm{t}$ ), respectively. Cdyn and Rrs measured in this study were not the exact $\mathrm{C}$ and Raw, but total compliance and resistance values that included resistance and elastic forces from the chest wall and the lung tissue [6,16-18]. However, the changes in total resistance and compliance reflect Raw and C $[6,19]$ and the effects of the chest wall and lung tissue would be little or unchanged, equally in all patients; therefore, this is unlikely to change our results. The advantage of using this technique is that data are displayed continuously; furthermore, these values have been shown to be accurate in previous studies $[5-7,11,16]$. Oikkonen and Tallgren [16] reported that Cdyn decreased immediately after insufflation and was not influenced by duration of pressurization, so the timing of our measurements of respiratory parameters was appropriate. Furthermore, data were mean values of three measurements taken when the displayed loop was not distorted.

During laparoscopy, peritoneal $\mathrm{CO}_{2}$ insufflation increases intra-abdominal pressure, elevates the diaphragm, and increases intra-thoracic pressure [20]. This leads to an increase in PIP and Raw as well as a decrease in functional residual capacity and pulmonary compliance $[5,16,20-23]$. Oikkonen and Tallgren [16] reported that there was no association between age, sex, BMI, duration of pressurization, or changes in Cdyn during laparoscopic surgery. Some studies have reported that the degree of muscle relaxation and smoking history have no significant effect on respiratory mechanics during mechanical ventilation $[6,17,24]$. However, other studies have reported that several factors (patient's position, BMI, anesthetic agents etc.) affect the extent of respiratory mechanics changes during laparoscopic surgery $[5,16,20,22,23]$. These changes could be aggravated in patients with pre-existing pulmonary diseases, or morbid obesity $[21,22]$, which is why we excluded these patients. In our study, there were no significant differences between the two groups 
with respect to these factors; the only difference was the type of anesthetic agent used.

Sevoflurane is known to act as a bronchodilator by directly relaxing bronchial smooth muscle and inhibiting vagal airway reflexes, similar to other inhalation anesthetics [4-9]. The mechanism of the direct relaxing effect of inhalation anesthetics on airway smooth muscle may involve a reduction of $\mathrm{Ca}^{2+}$ concentration and perturbation of calcium homeostasis $[9,19]$. Sevoflurane may also have a protective effect against airway constriction [7,9]. Sivaci et al. [5] reported that sevoflurane significantly reduced Rrs in laparoscopic surgery.

Propofol has also been reported to prevent bronchoconstriction and to induce bronchodilatation under mechanical ventilation by anticholinergic effects on the airway [11-13]. Propofol also has direct relaxant effects on airway smooth muscle $[10,13,25]$. Although the exact mechanism of action of propofol is still unknown, it has been postulated that it reduces the influx of calcium ions in vitro [13,25].

Opioids increase pulmonary resistance and decrease pulmonary compliance. These changes are not caused by a change in the autonomic nervous system or airway smooth muscle, but spasm of the chest wall muscles that can be abolished by neuromuscular blockers $[14,15]$. Intravenous lidocaine has been shown to have bronchodilatory effects in vitro and in vivo $[17,26]$. However, it has no bronchodilatory effect at clinical concentrations, and does not protect against bronchoconstriction [17,27]. Thus infusion of remifentanil and $20 \mathrm{mg}$ lidocaine in group PR may have had little influence on respiratory mechanics in our study.

To the best of our knowledge, only one previous report has compared respiratory mechanics under propofol and sevoflurane anesthesia during laparoscopy; the present study represents the first clinical study. Puglisi et al. [4] reported that sevoflurane resulted in significantly higher airway pressure than propofol during laparoscopy in a porcine model. They argued that propofol had a stronger relaxant action on the airway muscles than sevoflurane. We did not find any significant differences in airway pressure between the two groups. There are several reasons for this discrepancy. First, we used remifentanil in group PR only, whereas Puglisi et al. used fentanyl in both groups. We cannot exclude the possibility that remifentanil may have affected pulmonary mechanics in group $\mathrm{PR}$, because we did not compare chest wall rigidity or extent of chest wall relaxation between the two groups. However, the influence of remifentanil on respiratory mechanics is likely to have been negligible, because we continuously infused muscle relaxant.
Second, there were differences in the amount of anesthetics used between our study and the previous study. Puglisi et al. used $12 \mathrm{mg} / \mathrm{kg} / \mathrm{hr}$ propofol, while we used approximately 8 $\mathrm{mg} / \mathrm{kg} / \mathrm{hr}$ in our study. We were not able to directly compare the amount of anesthetics because they did not specify the concentration of sevoflurane they used. However, because we did not use remifentanil in group $\mathrm{S}$, we might have used relatively higher concentration of sevoflurane in proportion to propofol than Puglisi and colleagues. Although there is controversy about whether inhalation anesthetics have a dose-dependent bronchodilatory effect $[7,8]$, relatively higher concentration of sevoflurane could explain the differences in results between the two studies. The exact mechanisms of airway relaxion by propofol and sevoflurane are still unknown. However, sevoflurane acts more by direct airway smooth muscle relaxation than vagolysis, while propofol acts the other way $[4,17,25,28]$. Although the exact mechanisms and bronchodilatory effects of propofol and sevoflurane have yet to be determined, sevoflurane might be a better bronchodilator than propofol.

Third, propofol may have reduced PIP by relaxing the chest wall muscle to a greater extent than sevoflurane in Puglisi and colleagues' study. Both sevoflurane and propofol are known to relax skeletal muscles $[29,30]$. If propofol is a stronger skeletal muscle relaxant than sevoflurane or used at a relatively higher dose than sevoflurane, it could have relaxed the chest wall muscle more effectively. If Puglisi et al. did not use muscle relaxant, this effect could have been exaggerated, resulting in a decrease in PIP greater than that observed for sevoflurane, in contrast to our study findings.

The limitations of the current study are listed below. This study was a single-blinded study. Furthermore, lack of invasive monitoring makes precise interpretation of respiratory and cardiovascular effects impossible. We did not compare propofol and sevoflurane directly; rather, we compared total intravenous anesthesia and sevoflurane, as this more closely reflects the clinical situation.

Respiratory mechanics can be adversely affected during laparoscopic colectomy. Among them, Rrs increased significantly more during propofol-remifentanil anesthesia than during sevoflurane anesthesia. Further controlled studies in patients with limited pulmonary reserves due to obesity or chronic obstructive pulmonary disease are needed.

\section{Acknowledgments}

This work was supported by Grant from Inje University, 2010. 


\section{References}

1. da Luz Moreira A, Kiran RP, Kirat HT, Remzi FH, Geisler DP, Church JM, et al. Laparoscopic versus open colectomy for patients with American Society of Anesthesiology (ASA) classifications 3 and 4: the minimally invasive approach is associated with significantly quicker recovery and reduced costs. Surg Endosc 2010; 24: 1280-6.

2. Degiuli M, Mineccia M, Bertone A, Arrigoni A, Pennazio M, Spandre M, et al. Outcome of laparoscopic colorectal resection. Surg Endosc 2004; 18: 427-32.

3. Henny CP, Hofland J. Laparoscopic surgery: pitfalls due to anesthesia, positioning, and pneumoperitoneum. Surg Endosc 2005; $19: 1163-71$.

4. Puglisi F, Crovace A, Staffieri F, Capuano P, Carravetta G, De Fazio M, et al. Comparison of hemodynamic and respiratory effects of propofol and sevoflurane during carbon dioxide pneumoperitoneum in a swine model. Chir Ital 2007; 59: 105-11.

5. Sivaci R, Orman A, Yilmazer M, Yilmaz S, Ellidokuz H, Polat C. The effect of low-flow sevoflurane and desflurane on pulmonary mechanics during laparoscopic surgery. J Laparoendosc Adv Surg Tech A 2005; 15: 125-9.

6. Goff MJ, Arain SR, Ficke DJ, Uhrich TD, Ebert TJ. Absence of bronchodilation during desflurane anesthesia: a comparison to sevoflurane and thiopental. Anesthesiology 2000; 93: 404-8.

7. Habre W, Peták F, Sly PD, Hantos Z, Morel DR. Protective effects of volatile agents against methacholine-induced bronchoconstriction in rats. Anesthesiology 2001; 94: 348-53.

8. Dikmen Y, Eminoglu E, Salihoglu Z, Demiroluk S. Pulmonary mechanics during isoflurane, sevoflurane and desflurane anaesthesia. Anaesthesia 2003; 58: 745-8.

9. Farber NE, Pagel PS, Warltier DC. Pulmonary pharmacology. In: Miller’s anesthesia. 7th ed. Edited by Miller RD: Philadelphia, Churchill Livingstone. 2009, pp 562-7.

10. Peratoner A, Nascimento CS, Santana MC, Cadete RA, Negri EM, Gullo A, et al. Effects of propofol on respiratory mechanic and lung histology in normal rats. Br J Anaesth 2004; 92: 737-40.

11. Eames WO, Rooke GA, Wu RS, Bishop MJ. Comparison of the effects of etomidate, propofol, and thiopental on respiratory resistance after tracheal intubation. Anesthesiology 1996; 84: 1307-11.

12. Conti G, Dell'Utri D, Vilardi V, De Blasi RA, Pelaia P, Antonelli M, et al. Propofol induces bronchodilation in mechanically ventilated chronic obstructive pulmonary disease patients. Acta Anaesthesiol Scand 1993; 37: 105-9.

13. Reves JG, Glass PA, Lubarsky DA, McEvoy MD, Martinez-Ruiz R. Intravenous anesthetics. In: Miller's anesthesia. 7th ed. Edited by Sessler D: Philadelphia, Churchill Livingstone. 2009, p 724.

14. Willette RN, Barcas PP, Krieger AJ, Sapru HN. Pulmonary resistance and compliance changes evoked by pulmonary opiate receptor stimulation. Eur J Pharmacol 1983; 91: 181-8.

15. Fukuda K. Opioids. In: Miller's anesthesia. 7th ed. Edited by Sessler D: Philadelphia, Churchill Livingstone. 2009, pp 781-2.

16. Oikkonen M, Tallgren M. Changes in respiratory compliance at laparoscopy: measurements using side stream spirometry. Can J Anaesth 1995; 42: 495-7.

17. Hirshman CA, Bergman NA. Factors influencing intrapulmonary airway calibre during anaesthesia. Br J Anaesth 1990; 65: 30-42.

18. Warner DO, Vettermann J, Brusasco V, Rehder K. Pulmonary resistance during halothane anesthesia is not determined only by airway caliber. Anesthesiology 1989; 70: 453-60.

19. Mazzeo AJ, Cheng EY, Bosnjak ZJ, Coon RL, Kampine JP. Differential effects of desflurane and halothane on peripheral airway smooth muscle. Br J Anaesth 1996; 76: 841-6.

20. Desmond J, Gordon RA. Ventilation in patients anaesthetized for laparoscopy. Can Anaesth Soc J 1970; 17: 378-87.

21. Suh MK, Seong KW, Jung SH, Kim SS. The effect of pneumoperitoneum and Trendelenburg position on respiratory mechanics during pelviscopic surgery. Korean J Anesthesiol 2010; 59: 329-34.

22. Salihoglu Z, Demiroluk S, Cakmakkaya S, Gorgun E, Kose Y. Influence of the patient positioning on respiratory mechanics during pneumoperitoneum. Middle East J Anesthesiol 2002; 16: 521-8.

23. Kim YB, Chang CH, Kim SY, Nam YT. Effect of BMI and patient positioning on airway pressures and respiratory compliance during laparoscopic surgery. Korean J Anesthesiol 2006; 50: 302-7.

24. Chassard D, Berrada K, Tournadre J, Boulétreau P. The effect of neuromuscular block on peak airway pressure and abdominal elastance during pneumoperitoneum. Anesth Analg 1996; 82: 525-7.

25. Yamakage M, Hirshman CA, Croxton TL. Inhibitory effects of thiopental, ketamine, and propofol on voltage-dependent Ca2+ channels in porcine tracheal smooth muscle cells. Anesthesiology 1995; 83: 1274-82.

26. Downes H, Gerber N, Hirshman CA. I.V. lignocaine in reflex and allergic bronchoconstriction. Br J Anaesth 1980; 52: 873-8.

27. Maslow AD, Regan MM, Israel E, Darvish A, Mehrez M, Boughton R, et al. Inhaled albuterol, but not intravenous lidocaine, protects against intubation-induced bronchoconstriction in asthma. Anesthesiology 2000; 93: 1198-204.

28. Vettermann J, Warner DO, Brichant JF, Rehder K. Halothane decreases both tissue and airway resistances in excised canine lungs. J Appl Physiol (1985) 1989; 66: 2698-703.

29. Haeseler G, Störmer M, Bufler J, Dengler R, Hecker H, Piepenbrock S, et al. Propofol blocks human skeletal muscle sodium channels in a voltage-dependent manner. Anesth Analg 2001; 92: 1192-8.

30. Ginz HF, Zorzato F, Iaizzo PA, Urwyler A. Effect of three anaesthetic techniques on isometric skeletal muscle strength. Br J Anaesth 2004; 92: $367-72$. 